\title{
Physical, Thermal and Spectral Properties of Biofield Treated 3-Nitroacetophenone
}

\author{
Mahendra Kumar Trivedi ${ }^{1}$, Rama Mohan Tallapragada ${ }^{1}$, Alice Branton ${ }^{1}$, Dahryn Trivedi ${ }^{1}$, \\ Gopal Nayak ${ }^{1}$, Rakesh Kumar Mishra ${ }^{2}$, Snehasis Jana ${ }^{2, *}$ \\ ${ }^{1}$ Trivedi Global Inc., Henderson, USA \\ ${ }^{2}$ Trivedi Science Research Laboratory Pvt. Ltd., Hall-A, Chinar Mega Mall, Chinar Fortune City, Hoshangabad Rd., Bhopal, Madhya \\ Pradesh, India
}

Email address:

publication@trivedisrl.com (S. Jana)

\section{To cite this article:}

Mahendra Kumar Trivedi, Rama Mohan Tallapragada, Alice Branton, Dahryn Trivedi, Gopal Nayak, Rakesh Kumar Mishra, Snehasis Jana. Physical, Thermal and Spectral Properties of Biofield Treated 3-Nitroacetophenone. Science Journal of Analytical Chemistry.

Vol. 3, No. 6, 2015, pp. 71-79. doi: 10.11648/j.sjac.20150306.11

\begin{abstract}
Nitroacetophenone (3-NAP) is an organic compound used as an intermediate for the synthesis of pharmaceutical agents. The aim of this study was to evaluate the impact of biofield energy treatment on the physical, thermal and spectral properties of 3-NAP. The study was performed in two groups i.e. control and treated. The control group remained as untreated, and the treated group received Mr. Trivedi's biofield energy treatment. The control and treated 3-NAP samples were further characterized by X-ray diffraction (XRD), differential scanning calorimetry (DSC), thermogravimetric analysis (TGA), laser particle size analyzer, surface area analyzer, Fourier transform infrared (FT-IR) spectroscopy, and ultra violet-visible spectroscopy (UV-vis) analysis. The XRD analysis showed decrease in crystallite size of treated 3-NAP by $20.27 \%$ as compared to the control sample. However, the XRD peaks of treated sample showed an increase in intensity as compared to the control. The DSC result showed a slight increase in melting temperature of treated 3-NAP $\left(80.75^{\circ} \mathrm{C}\right)$ with respect to the control $\left(79.39^{\circ} \mathrm{C}\right)$. The latent heat of fusion of treated 3-NAP was changed by $16.28 \%$ as compared to the control sample. The TGA analysis showed an increase in onset temperature of treated sample $\left(192^{\circ} \mathrm{C}\right)$ as compared to the control sample $\left(182^{\circ} \mathrm{C}\right)$. Further, the maximum thermal decomposition temperature $\left(\mathrm{T}_{\max }\right)$ of treated 3-NAP was increased as compared to the control. This showed the increase in thermal stability of treated 3-NAP with respect to control. The treated 3-NAP showed an increase in average particle size $\left(\mathrm{d}_{50}\right)$ by $27.6 \%$ along with an increase in size exhibited by $99 \%$ of particles $\left(\mathrm{d}_{99}\right)$ by $4.9 \%$ as compared to the control. Brunauer-Emmett-Teller (BET) analysis showed a substantial decrease in surface area by $24.6 \%$ with respect to the control. The FT-IR analysis showed an emergence of peak at $1558 \mathrm{~cm}^{-1}$ in treated 3-NAP sample as compared to the control. Nevertheless, the UV spectral analysis of treated 3-NAP showed no alterations in absorption peaks as compared to the control. Altogether, the result showed that biofield energy treatment has altered the physical, thermal and spectral properties of treated 3-NAP as compared to the control.
\end{abstract}

Keywords: X-Ray Diffraction, Thermal Analysis, Laser Particle Size Analysis, Surface Area Analysis, Fourier Transform Infrared Spectroscopy, Ultra Violet-Visible Spectroscopy

\section{Introduction}

Nitroaromatic compounds are one of the important group of industrial chemicals in use today. These organic compounds consist of at least one $-\mathrm{NO}_{2}$ group which is attached to the aromatic ring [1]. Many pharmaceuticals are originated from nitroaromatic compounds. For instance, many substituted nitroaromatic compounds are used to synthesize the diverse collection of indoles that are bioactive components of many drugs and agrochemicals [2]. Nitroacetophenone are nitroaromatic compounds that have been commonly used in the synthesis of chemical and pharmaceutical compounds. 4-Nitroacetophenone based compounds are recently recognized as a class of antitrypanosomal drug candidates [3]. 2-Nitroacetophenone is used as an intermediate for the synthesis of cinoxacin that is prescribed for urinary tract infections in adults [4]. 3Nitroacetophenone (3-NAP) is a compound used as 
intermediate for the synthesis of flurbiprofen that is administered for the treatment of inflammation and arthritis pain [5]. Iradyan et al. synthesized 3-NAP derivatives and investigated its antitumor efficiency [6]. Chalcones are an important class of compounds associated with excellent pharmacological activity [7]. Chalcones are synthesized from 3-NAP as an intermediate compound, which have profound anti-inflammatory [8], anti-ulcerative [9], antibacterial [10], antifungal [11] and antimalarial activities [12]. Pharmaceutical stability is a key factor that determines the therapeutic efficacy and toxicity of medications. According to Food and Drug Administration (FDA), the drug companies should determine a time limit to which they can assure the full potency and safety of the medications [13]. Therefore, chemical and physical stability of the pharmaceutical compounds are more desired quality attributes that directly affect its safety, efficacy, and shelf life [14]. Thus, exploring new methods that can improve the physicochemical properties of active pharmaceutical ingredients will be like the gold standard in the pharmaceutical development. Recently biofield energy treatment was utilized as novel method for changing the physical and thermal properties of various materials such as metals [15, 16], ceramics [17], organic product [18] and spectral properties of various pharmaceutical drugs [19]. Therefore author planned to study the influence of biofield energy treatment on the physical, thermal and spectral properties of 3-NAP.

In United States the National Centre for Complementary and Alternative Medicine (NCCAM), which is a part of the prestigious National Institute of Health $(\mathrm{NIH})$, authorizes the use of Complementary and Alternative Medicine (CAM) therapies as an alternative in the healthcare sector. According to an estimate about $36 \%$ of Americans regularly uses some form of CAM [20], in their day-to-day activities. CAM embraces numerous energy-healing therapies; biofield therapy is one of the energy medicine used worldwide to alleviate overall human health.

Biofield energy treatment consists of practices based on subtle energy field and generally reflect the concept that human being are infused with this form of energy [21]. Researchers have shown that a unique bioenergetic field surrounds and permeates the human body [22]. This bioenergetic field regulates the human health and during disease condition this unique field is depleted [23]. Recently some medical technologies were used to measure this human biofield [24].

Therefore, it is envisaged that human beings have the ability to harness the energy from the environment/Universe and can transmit into any object (living or non-living) around the Globe. The object(s) will always receive the energy and responding in a useful manner that is called biofield energy. Mr. Trivedi is known to transform the characteristics of various living and non-living things using his unique biofield energy. This biofield energy treatment is also known as The Trivedi Effect ${ }^{\circledR}$. It is known to change the phenotype characteristics of microbes $[25,26]$ and improved the growth and anatomical characteristics of medicinal plants [27, 28].
Due to pharmaceutical significance of 3-NAP as an intermediate and literature reports on biofield energy treatment as a useful approach, the present work was undertaken to evaluate the impact of this treatment on physical, thermal and spectral properties of 3-NAP.

\section{Materials and Methods}

3-Nitroacetophenone (3-NAP) was procured from S D Fine Chemicals Limited, India. The sample was divided into two parts; one was kept as the control sample while the other was subjected to Mr. Trivedi's unique biofield energy treatment and coded as treated sample. The treated sample was in sealed pack and handed over to Mr. Trivedi for biofield energy treatment under laboratory condition. Mr. Trivedi gave the energy treatment through his unique energy transmission process to the treated samples without touching it. The control and treated samples were further characterized by various analytical techniques such as X-ray diffraction, differential scanning calorimetry, thermogravimetric analysis, laser particle size analyzer, surface area analyzer, Fourier transform infrared spectroscopy, and ultra violet-visible spectroscopy analysis.

\subsection{X-ray Diffraction (XRD) Study}

XRD analysis of control and treated 3-NAP was evaluated using X-ray diffractometer system, Phillips, Holland PW 1710 which consist of a copper anode with nickel filter. XRD system had a radiation of wavelength $1.54056 \AA$. The average crystallite size $(G)$ was computed using formula:

$$
\mathrm{G}=\mathrm{k} \lambda /(\mathrm{b} \operatorname{Cos} \theta)
$$

Here, $\lambda$ is the wavelength of radiation used, $b$ is full width half-maximum (FWHM) of peaks and $\mathrm{k}$ is the equipment constant $(=0.94)$. Percentage change in average crystallite size was calculated using following formula:

Percentage change in crystallite size $=\left[\left(\mathrm{G}_{\mathrm{t}}-\mathrm{G}_{\mathrm{c}}\right) / \mathrm{G}_{\mathrm{c}}\right] \times 100$

Where, $G_{c}$ and $G_{t}$ are denoted as crystallite size of control and treated powder samples respectively.

\subsection{Differential Scanning Calorimetry (DSC)}

The control and treated 3-NAP samples were analyzed using Pyris-6 Perkin Elmer DSC at a heating rate of $10^{\circ} \mathrm{C} / \mathrm{min}$ under air atmosphere and the air was flushed at a flow rate of $5 \mathrm{~mL} / \mathrm{min}$. The predetermined amount of sample was kept in an aluminum pan and closed with a lid. A blank aluminum pan was used as a reference. The percentage change in latent heat of fusion was calculated using following equations:

$$
\begin{aligned}
& \% \text { change in Latent heat of fusion } \\
& =\frac{\left[\Delta \mathrm{H}_{\text {Treated }}-\Delta \mathrm{H}_{\text {Control }}\right]}{\Delta \mathrm{H}_{\text {Control }}} \times 100
\end{aligned}
$$

Where, $\Delta \mathrm{H}_{\text {Control }}$ and $\Delta \mathrm{H}_{\text {Treated }}$ are represented as the latent heat of fusion of control and treated samples, respectively. 


\subsection{Thermogravimetric Analysis-Differential Thermal Analysis (TGA-DTA)}

A Mettler Toledo simultaneous TGA and Differential thermal analyzer (DTA) was used to investigate the thermal stability of control and treated 3-NAP samples. The heating rate was $5^{\circ} \mathrm{C} / \mathrm{min}$ and the samples were heated in the range of room temperature to $400^{\circ} \mathrm{C}$ under air atmosphere.

\subsection{Particle Size Analysis}

A Sympetac Helos-BF laser particle size analyzer was used to evaluate the particle size distribution of 3-NAP samples using a measurement range of 0.1 to $875 \mu \mathrm{m}$. The average particle size $d_{50}$ and $d_{99}$ size showed by $99 \%$ of powder particles were calculated. The percentage changes in $\mathrm{d}_{50}$ and $\mathrm{d}_{99}$ values were computed using following formula:

Percentage change in $d_{50}$ size $=100 \times\left(d_{50}\right.$ treated $-d_{50}$ control)/ $\mathrm{d}_{50}$ control

Percentage change in $\mathrm{d}_{99}$ size $=100 \times\left(\mathrm{d}_{99}\right.$ treated $-\mathrm{d}_{99}$ control)/ $\mathrm{d}_{99}$ control

\subsection{Surface Area Analysis}

A SMART SORB 90 Brunauer-Emmett-Teller (BET) surface area analyzer with a detection range of $0.2-1000 \mathrm{~m}^{2} / \mathrm{g}$ was used to evaluate the surface area of 3-NAP samples. The samples were analyzed using a standard ASTM D 5604 method. The Percent changes in surface area were computed using following formula:
$\%$ change in surface area $=\frac{\left[\mathrm{S}_{\text {Treated }}-\mathrm{S}_{\text {Control }}\right]}{\mathrm{S}_{\text {Control }}} \times 100$

Where, $\mathrm{S}_{\text {Control }}$ and $\mathrm{S}_{\text {Treated }}$ are the surface area of control and treated samples respectively.

\subsection{FT-IR Spectroscopy}

The FT-IR spectra were recorded on Shimadzu's Fourier transform infrared spectrometer (Japan) with the frequency range of $4000-500 \mathrm{~cm}^{-1}$. The analysis was accomplished to evaluate the effect of biofield treatment at the atomic level like dipole moment, force constant and bond strength in chemical structure [29]. The treated sample was divided into two parts T1 and T2 for FT-IR analysis.

\subsection{UV-Vis Spectroscopic Analysis}

A Shimadzu UV-2400 PC series spectrophotometer with 1 $\mathrm{cm}$ quartz cell and a slit width of $2.0 \mathrm{~nm}$ was used to obtain the UV spectra of the control and treated 3-NAP samples. The spectroscopic analysis was carried out using wavelength in the range of $200-400 \mathrm{~nm}$ and methanol was used as a solvent. The UV spectra were analyzed to determine the effect of biofield treatment on the energy gap of highest occupied molecular orbital (HOMO) and lowest unoccupied molecular orbital (LUMO) [29]. The treated sample was divided in two parts $\mathrm{T} 1$ and $\mathrm{T} 2$ for the UV-Vis spectroscopic analysis.
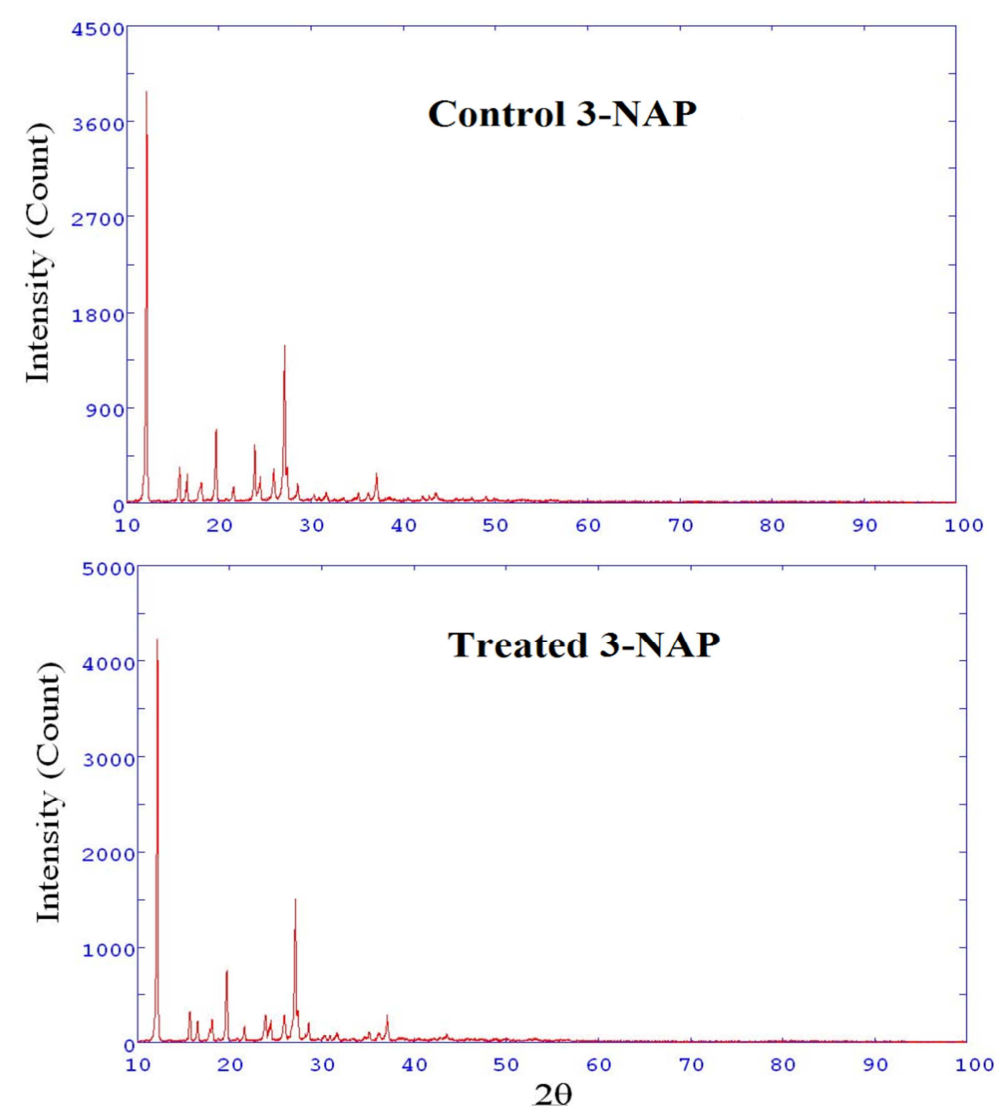

Fig. 1. XRD diffractograms of control and treated 3-nitroacetophenone. 


\section{Results and Discussion}

\subsection{XRD Study}

XRD studies were used to investigate the crystalline nature of the control and treated samples. Fig. 1 shows the XRD diffractograms of control and treated 3-NAP samples. XRD diffractogram of control 3-NAP showed intense crystalline peaks at $12.19^{\circ}, 15.77^{\circ}, 16.57^{\circ}, 19.73^{\circ}, 23.90^{\circ}$, $24.50^{\circ}, 25.98^{\circ}, 27.14^{\circ}, 27.42^{\circ}$, and $37.10^{\circ}$. However, the treated sample showed intense crystalline peaks at $12.20^{\circ}$, $15.68^{\circ}, 15.78^{\circ}, 16.57^{\circ}, 19.73^{\circ}, 23.96^{\circ}, 24.50^{\circ}, 25.97^{\circ}$, $27.16^{\circ}, 27.46^{\circ}$, and $37.08^{\circ}$. The intensity of XRD peaks at Bragg's (2 $\theta$ ) angle $12.20^{\circ}, 15.68^{\circ}, 19.73^{\circ}$, and $27.16^{\circ}$ in treated samples were increased as compared to the control sample. This showed the probable increase in crystallinity of the treated 3-NAP as compared to the control sample. Inoue et al. showed that an alteration in crystal morphology might cause the changes in intensity of the XRD peaks [30]. Hence, it is assumed that biofield treatment might cause changes in crystal morphology of the treated 3-NAP that may lead to increase in the intensity of the XRD peaks as compared to the control.

The crystallite size an important crystallographic factor was computed using the Scherrer formula and the results are depicted in Fig. 2. The crystallite size of control 3-NAP was $81.45 \mathrm{~nm}$ while it was decreased to $64.94 \mathrm{~nm}$ in the treated sample. The result showed $20.27 \%$ decrease in crystallite size of the treated sample as compared to the control sample. It was reported that presence of internal strain and increase in atomic displacements from their ideal lattice positions causes a reduction in crystallite size [31]. Crystallite size reduction is perhaps the most distinguished feature of mechanochemical treatment. Many researchers have shown that average crystallite size of ceramics or metal powders decreases rapidly during milling [32-35]. Dittrich et al. showed that mechanical milling method caused a substantial decrease in crystallite size [36]. Hence, it is assumed that biofield treatment may provide the energy that caused an increase in strain and displacement in ideal lattice positions of treated 3-NAP sample that caused a decrease in the crystallite size.

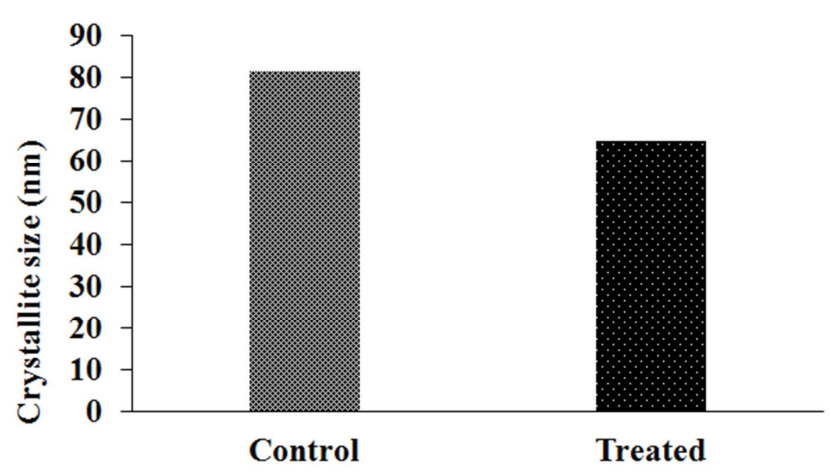

Fig. 2. Crystallite size of control and treated 3-nitroacetophenone.

\subsection{DSC Study}

DSC thermograms of control and treated 3- NAP are presented in Fig. 3. DSC thermogram of control 3-NAP showed an intense endothermic peak at $79.39^{\circ} \mathrm{C}$ that was due to melting temperature of the sample. However, the treated 3NAP showed an endothermic peak at $80.75^{\circ} \mathrm{C}$ due to melting temperature of the treated sample. This suggests the slight increase in melting temperature of treated sample as compared to the control. It is assumed that intermolecular interaction forces are more pronounced in treated 3-NAP that leads to increase in the packing of the molecules and increase in melting temperature.

The latent heat of fusion of control and treated 3-NAP samples were obtained from the DSC thermogram and data are presented in Table 1. The latent heat of fusion of control 3-NAP was $119.72 \mathrm{~J} / \mathrm{g}$, and it was decreased to $100.23 \mathrm{~J} / \mathrm{g}$ in the treated sample. The results suggested the $16.28 \%$ decrease in the latent heat of fusion of the treated 3-NAP as compared to the control sample. Latent heat of fusion is the energy absorbed in a material during its phase change from solid to liquid. It is assumed here that biofield energy treatment might cause alteration in the internal energy that might lead to change in latent heat of fusion of the treated sample.
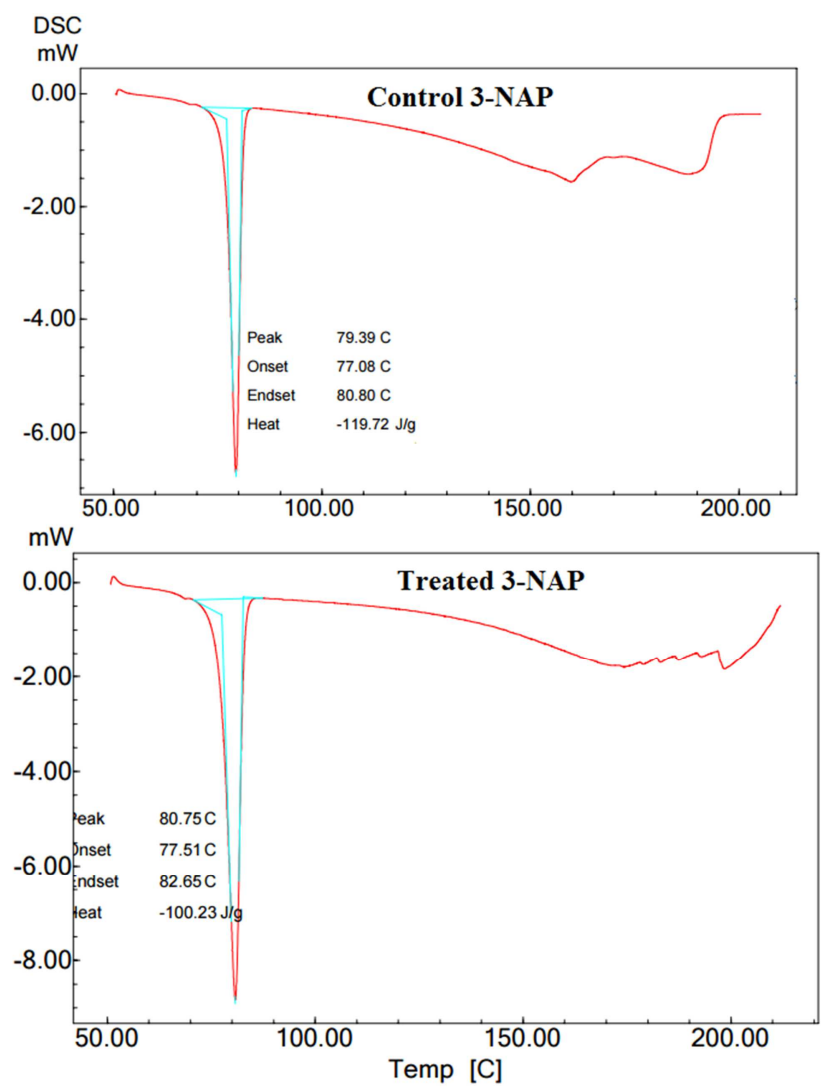

Fig. 3. DSC thermograms of control and treated 3-nitroacetophenone.

\subsection{TGA Study}

Thermogravimetric analysis was used to investigate the 
thermal stability of the control and treated 3-NAP. The TGA thermogram of control and treated samples are presented in Fig. 4. TGA thermogram of control 3-NAP showed onset temperature at around $182^{\circ} \mathrm{C}$ and end set temperature at around $229^{\circ} \mathrm{C}$. During this thermal process, the sample lost $53.67 \%$ of its initial weight. However, the treated 3-NAP showed onset temperature at around $192^{\circ} \mathrm{C}$ and the end set temperature was found at $223^{\circ} \mathrm{C}$. The treated 3-NAP lost around $46.94 \%$ weight during this process. The result showed the increase in onset temperature of thermal decomposition of treated sample as compared to the control. This indicated the increase in thermal stability of the treated sample as compared to the control.

The DTA thermogram of control and treated 3-NAP are depicted in Fig. 4. DTA thermogram of control 3-NAP showed two endothermic transitions in the sample. The former peak at $79.03^{\circ} \mathrm{C}$ was due to melting temperature of the sample and later peak at $209.94^{\circ} \mathrm{C}$ was due to thermal decomposition of the sample. Similarly, the treated sample showed endothermic peaks at $78.81^{\circ} \mathrm{C}$ and $211.93^{\circ} \mathrm{C}$. This showed an increase in thermal decomposition temperature of the treated 3-NAP as compared to the control.

The DTG thermogram of control and treated 3-NAP samples are presented in Fig. 4. DTG thermogram of control sample showed maximum thermal decomposition temperature $\left(\mathrm{T}_{\max }\right)$ at $200.80^{\circ} \mathrm{C}$ and it was increased up to $206.93^{\circ} \mathrm{C}$ in the treated 3-NAP. Overall, the increase in onset temperature, $\mathrm{T}_{\max }$ and reduction in weight loss of treated sample indicated an increase in thermal stability of treated 3NAP as compared to the control. DTA analysis also supported the above observation.

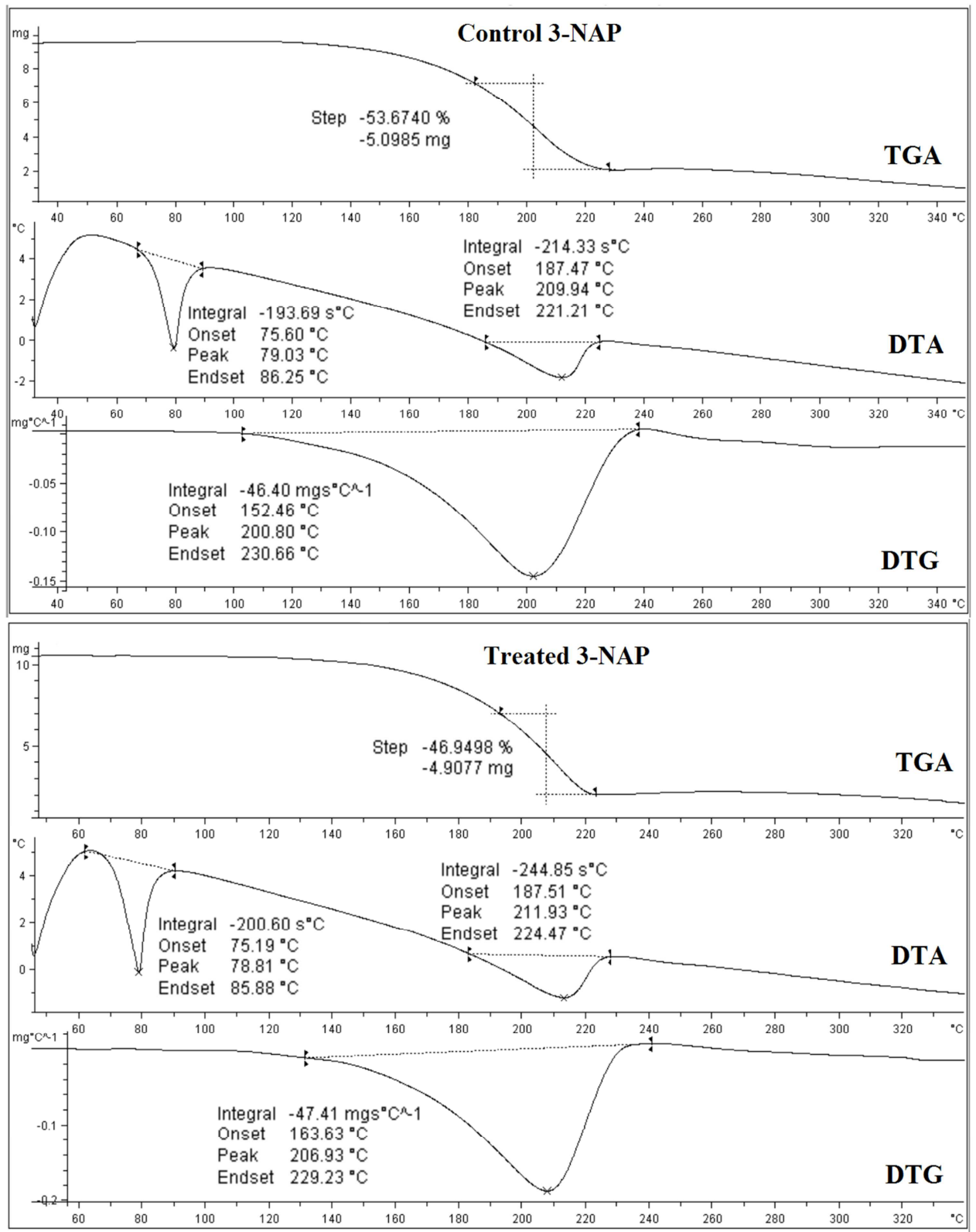

Fig. 4. TGA thermograms of control and treated 3-nitroacetophenone. 
Table 1. Thermal analysis data of control and treated 3-nitroacetophenone.

\begin{tabular}{lll}
\hline Parameter & Control & Treated \\
\hline Latent heat of fusion $\Delta \mathrm{H}(\mathrm{J} / \mathrm{g})$ & 119.72 & 100.23 \\
Melting temperature $\left({ }^{\circ} \mathrm{C}\right)$ & 79.39 & 80.75 \\
$\mathrm{~T}_{\max }\left({ }^{\circ} \mathrm{C}\right)$ & 200.80 & 206.93 \\
Weight loss $(\%)$ & 53.67 & 46.94 \\
\hline
\end{tabular}

\subsection{Particle Size and Surface Area Analysis}

The particle size of the control and treated 3-NAP samples were analyzed by laser particle size analyzer, and the data are presented in Fig. 5. The average particle size $\left(\mathrm{d}_{50}\right)$ and size exhibited by $99 \%$ of the particles $\left(d_{99}\right)$ were obtained from the particle size distribution curve. The average particle size of the control 3-NAP was $204.39 \mu \mathrm{m}$ and increased to 260.81 $\mu \mathrm{m}$ in the treated sample. Whereas the $\mathrm{d}_{99}$ of the control 3NAP was $658.17 \mu \mathrm{m}$ and increase up to $690.20 \mu \mathrm{m}$ in the treated sample. The results suggested the 27.6 and $4.9 \%$ increase in $\mathrm{d}_{50}$ and $\mathrm{d}_{99}$, respectively of the treated sample as compared to the control. Vinila et al. showed that particle size of a ceramic material increases with elevation in temperature [37]. Additionally, Iqbal et al. suggested that due to annealing the particles collide and coalesce with one another to form a bigger particle [38]. Hence, it is assumed here that biofield treatment may provide the energy that causes a collision, and coalescence in the treated 3-NAP particles leading to the formation of bigger particles.

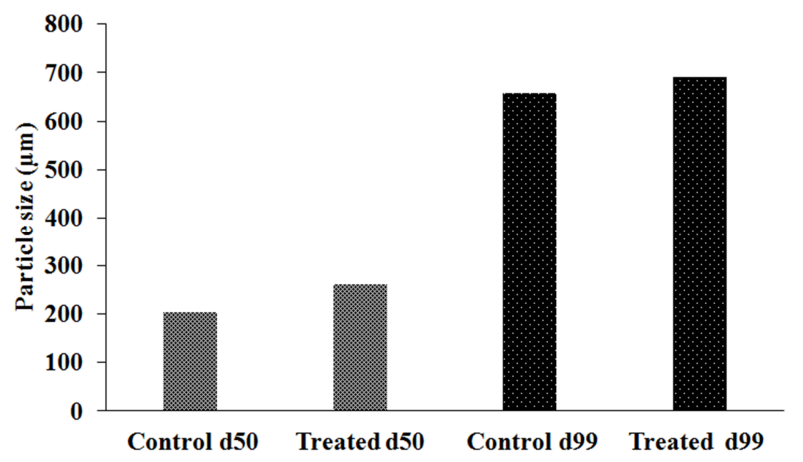

Fig. 5. Particle size ( $d_{50}$ and $\left.d_{99}\right)$ of control and treated 3-nitroacetophenone.

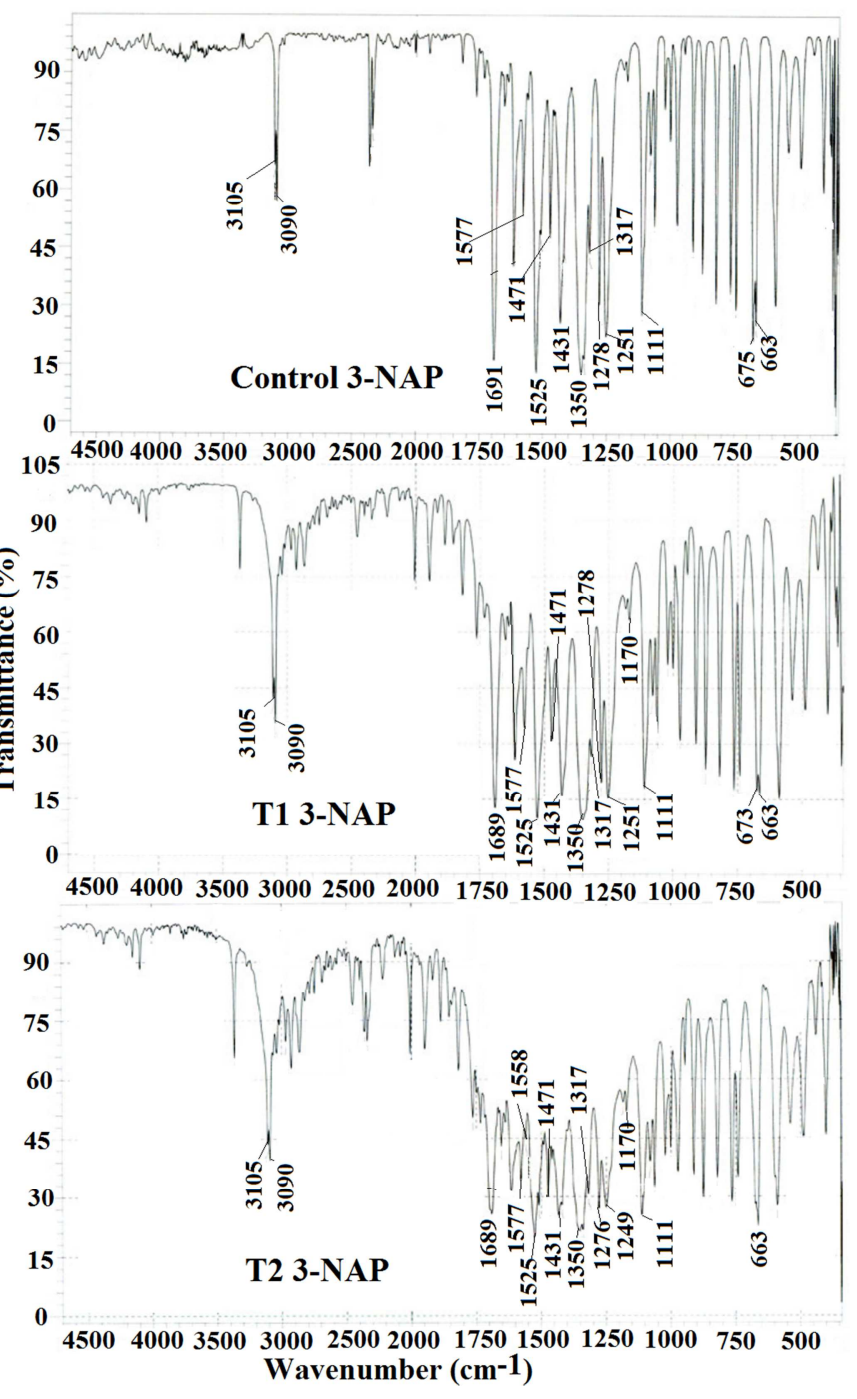

Fig 6. FT-IR spectra of control and treated 3-nitroacetophenone (T1 and T2). 
BET was used to investigate the surface area of control and treated 3-NAP samples. The surface area of the control sample was $0.5910 \mathrm{~m}^{2} / \mathrm{g}$, and it was decrease to $0.4455 \mathrm{~m}^{2} / \mathrm{g}$ in the treated sample. The result suggested the $24.6 \%$ decrease in surface area of the treated 3-NAP as compared to the control. The particle size is inversely proportional to surface area. Hence, an increase in particle size decreases the surface area and vice versa. Therefore, the increase in $\mathrm{d}_{50}$ and $d_{99}$ probably caused a resultant decrease in the surface area of the treated sample.

\subsection{FT-IR Spectroscopy}

FT-IR spectroscopy was used to investigate the spectral changes in the sample after biofield treatment. FT-IR spectra of control and treated 3-NAP are presented in Fig. 6. The FTIR spectrum of control, T1, and T2 samples showed methyl ($\mathrm{CH}_{3}$ ) stretching vibration peaks at 3090 and $3105 \mathrm{~cm}^{-1}$ respectively. The characteristic carbonyl $(\mathrm{C}=\mathrm{O})$ group stretching was noticed at $1691 \mathrm{~cm}^{-1}$ in control sample while in T1 and T2 it appeared at $1689 \mathrm{~cm}^{-1}$. The FT-IR spectrum of control 3-NAP, T1 and T2 showed absorptions peaks in the region of $1317-1350 \mathrm{~cm}^{-1}$ that was due to the symmetric vibration of the $\mathrm{NO}_{2}$ group. The $\mathrm{C}=\mathrm{C}$ (aromatic) stretching peaks were observed at 1471,1525 , and $1577 \mathrm{~cm}^{-1}$ in the control sample, while $\mathrm{T} 1$ sample showed at 1471, 1525, and $1577 \mathrm{~cm}^{-1}$. Whereas, the $\mathrm{T} 2$ sample showed $\mathrm{C}=\mathrm{C}$ stretching at $1471,1525,1558$, and $1577 \mathrm{~cm}^{-1}$. The $\mathrm{C}-\mathrm{C}$ stretching was observed at $1431 \mathrm{~cm}^{-1}$ in control, T1, and T2 samples. The vibration peaks in the region of $1251-1278 \mathrm{~cm}^{-1}$ were due C$\mathrm{N}$ stretching mode in the control and $\mathrm{T} 1$ samples. Whereas the T2 sample showed C-N stretching peak at 1249-1276 $\mathrm{cm}^{-}$ 1. The $\mathrm{C}-\mathrm{H}$ in plane bending was noticed at $1111 \mathrm{~cm}^{-1}$ in the control sample while the $\mathrm{T} 1$ and $\mathrm{T} 2$ sample showed in the region of $1111-1170 \mathrm{~cm}^{-1}$. The $\mathrm{C}-\mathrm{H}$ out of plane bending peaks in the control sample was in the region of $663-675 \mathrm{~cm}^{-}$ 1 . However, the T1 and T2 sample showed $\mathrm{C}-\mathrm{H}$ out of plane bending peaks at $663,673 \mathrm{~cm}^{-1}$ and $663 \mathrm{~cm}^{-1}$. Overall, the FT-IR results showed an emergence of new peak at $1558 \mathrm{~cm}^{-}$ ${ }^{1}$ in the treated 3-NAP (T2) sample as compared to control. It is assumed that biofield treatment might induce some alteration in $\mathrm{C}=\mathrm{C}$ (aromatic) stretching peak of the treated sample (T2) that lead to emergence of this new peak.

\section{6. $U$ V-vis Spectroscopy}

UV-vis spectra of control and treated 3-NAP are presented in Fig. 7. The UV spectra of control 3-NAP showed an absorption peak at $225 \mathrm{~nm}$. Similarly, the treated 3-NAP samples (T1 and T2) showed absorption peak at $225 \mathrm{~nm}$. Hence, the result showed no change in absorption peak of treated sample as compared to the control sample. Therefore, it is suggested that the biofield treatment did not disturb the energy gap between HOMO-LUMO [29] in treated sample, and it was found similar to the control sample.

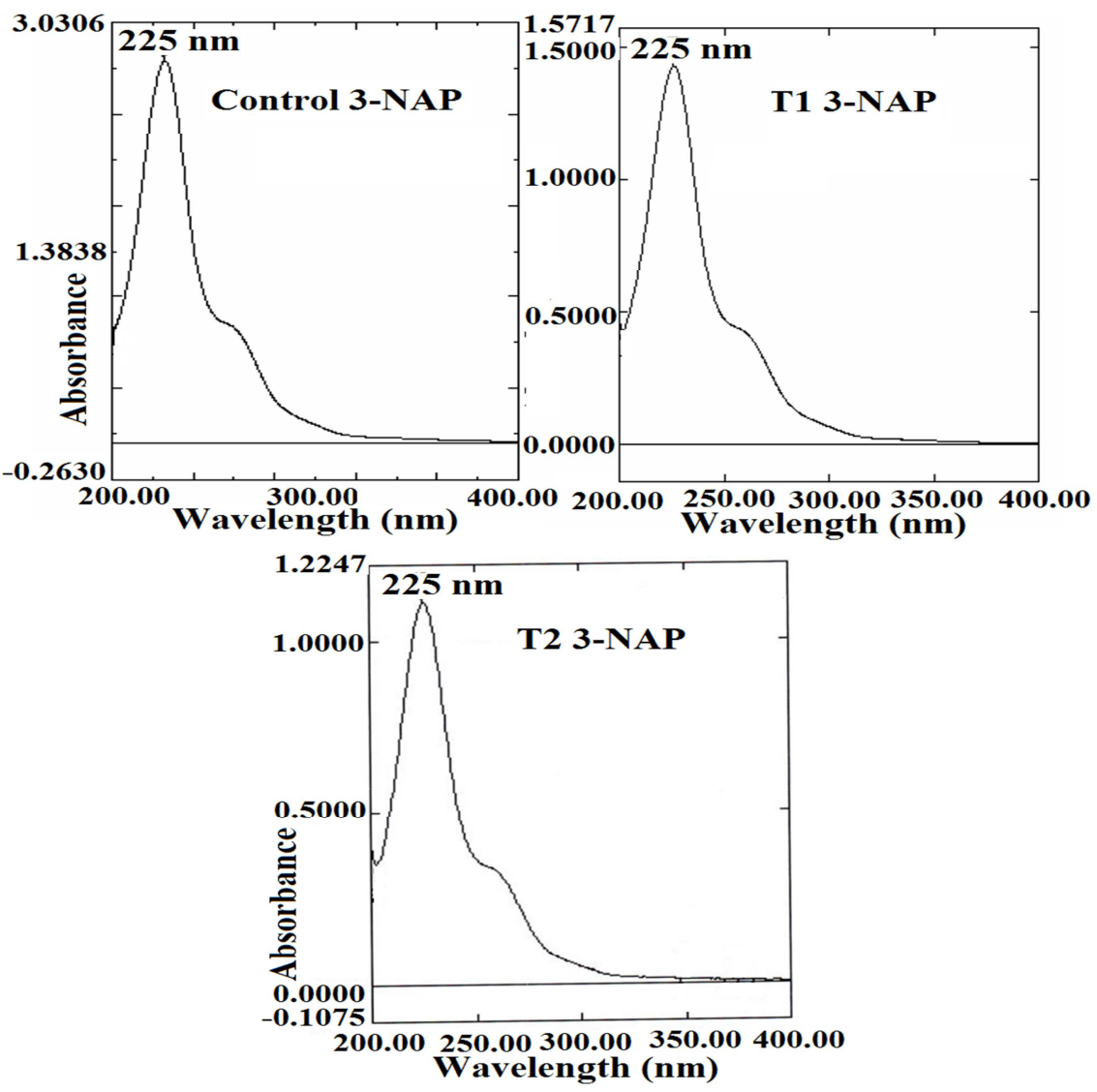

Fig. 7. UV spectra of control and treated 3-nitroacetophenone (T1 and T2). 


\section{Conclusions}

In summary, XRD data revealed the decrease in crystallite size of treated sample by $20.27 \%$ and an increase in the intensity of peaks as compared to the control sample. It is assumed that biofield treatment may provide the energy that caused an increase in strain and displacement of ideal lattice positions leading to decrease in crystallite size. DSC analysis showed a change in the latent heat of fusion of treated $3-\mathrm{NAP}$ by $16.28 \%$ with respect to the control sample. TGA analysis revealed the increase in thermal stability of treated 3-NAP, which was evidenced by an increase in $\mathrm{T}_{\max }$ and onset temperature of the treated sample. Additionally, reduction in weight loss of treated 3NAP was noticed as compared to the control. Particle size analysis showed an increase in $\mathrm{d}_{50}$ and $\mathrm{d}_{99}$ by 27.6 and $4.9 \%$, respectively as compared to the control sample. It is assumed that biofield treatment provided the energy that caused treated 3-NAP particles to coalesce with one another to form bigger microparticles. BET analysis showed a substantial decrease in surface area of treated sample that was supported by an increase in particle size. FT-IR analysis showed an emergence of new peak at $1558 \mathrm{~cm}^{-1}$ after biofield treatment in 3-NAP as compared to the control sample. Overall, the result demonstrated that biofield energy treatment has affected the physical, thermal and spectral properties of treated 3-NAP. It is assumed that biofield treated 3-NAP could be used as intermediate for synthesis of pharmaceutical compounds.

\section{Abbreviations}

XRD: X-ray diffraction; DSC: Differential scanning calorimetry; TGA: Thermogravimetric analysis; FTIR: Fourier transform infrared; UV-vis: Ultra violet-visible; CAM: Complementary and Alternative Medicine; FDA: Food and drug administration.

\section{Acknowledgment}

The authors wish to thank all the laboratory staff of MGV Pharmacy College, Nashik for their kind assistance during handling the various instrument characterizations. The authors would also like to thank Trivedi Science, Trivedi Master Wellness and Trivedi Testimonials for their support during the work.

\section{References}

[1] Ju KS, Parales RE (2010) Nitroaromatic compounds, from synthesis to biodegradation. Microbiol Mol Biol Rev 74: 250272 .

[2] Dalpozzo R, Bartoli G (2005) Bartoli indole synthesis. Curr Org Chem 9: 163-178.
[3] Perez-Rebolledo A, Teixeira LR, Batista AA, Mangrich AS, Aguirre G, et al. (2008) 4- Nitroacetophenone-derived thiosemicarbazones and their copper(II) complexes with significant in vitro anti-trypanosomal activity. Eur J Med Chem 43: 939-948.

[4] Vardanyan R, Hruby V (2006) Synthesis of essential drugs. (1stedn), Elsevier, Amsterdam, The Netherlands.

[5] Britain HG (2012) Profiles of drug substances, excipients and related methodology. Academic Press.

[6] Iradyan MA, Aroyan RA, Stepanya GM, Arsenya FG, Garibdzhanyan BT (2008) Imidazole derivatives. XXX. Synthesis and antitumor activity of 4-amyloxy-3 nitroacetophenone 2-imidazolinyl-2-hydrazone and related compounds. Pharm chem J 42: 384-386.

[7] Gomez-Rivera A, Aguilar-Mariscal H, Romero-Ceronio N, Roa-de la Fuente LF, Lobato-Garcia CE (2013) Synthesis and anti-inflammatory activity of three nitro chalcones. Bioorg Med Chem Lett 23: 5519-5522.

[8] Peng F, Wang G, Li X, Cao D, Yang Z, et al. (2012) Rational design, synthesis, and pharmacological properties of pyranochalcone derivatives as potent anti-inflammatory agents. Eur J Med Chem 54: 272-280.

[9] Shibuya A, Onda K, Kawahara H, Uchiyama Y, Nakayama H, et al. (2010) Sofalcone, a gastric mucosa protective agent, increases vascular endothelial growth factor via the Nrf2heme-oxygenase-1 dependent pathway in gastric epithelial cells. Biochem Biophys Res Commun 398: 581-584.

[10] Konduru NK, Dey S, Sajid M, Owais M, Ahmed N (2013) Synthesis and antibacterial and antifungal evaluation of some chalcone based sulfones and bisulfones. Eur J Med Chem 59: 23-30.

[11] Liu YT, Sun XM, Yin DW, Yuan F (2013) Syntheses and biological activity of chalcones-imidazole derivatives. Res Chem Intermed 39: 1037-1048.

[12] Yadav N, Dixit SK, Bhattacharya A, Mishra LC, Sharma M, et al. (2012) Antimalarial activity of newly synthesized chalcone derivatives In vitro. Chem Biol Drug Des 80: 340-347.

[13] Du B, Daniels VR, Vaksman Z, Boyd JL Crady C, et al. (2011) Evaluation of physical and chemical changes in pharmaceuticals flown on space missions. AAPS J, 13: 299308 .

[14] Blessy M, Patel RD, Prajapati PN, Agrawal YK (2014) Development of forced degradation and stability indicating studies of drugs- A review. J Pharm Anal 4: 159-165.

[15] Trivedi MK, Patil S, Tallapragada RM (2013) Effect of biofield treatment on the physical and thermal characteristics of silicon, tin and lead powders. J Material Sci Eng 2: 125.

[16] Trivedi MK, Patil S, Tallapragada RMR (2015) Effect of biofield treatment on the physical and thermal characteristics of aluminium powders. Ind Eng Manag 4: 151.

[17] Trivedi MK, Patil S, Tallapragada RM (2013) Effect of biofield treatment on the physical and thermal characteristics of vanadium pentoxide powder. J Material Sci Eng S11: 001.

[18] Trivedi MK, Nayak G, Patil S, Tallapragada RM, Jana S, et al. (2015) Bio-field treatment: An effective strategy to improve the quality of beef extract and meat infusion powder. J Nutr Food Sci 5: 389. 
[19] Trivedi MK, Patil S, Shettigar H, Bairwa K, Jana S (2015) Effect of biofield treatment on spectral properties of paracetamol and piroxicam. Chem Sci J 6: 98.

[20] Barnes PM, Powell-Griner E, McFann K, Nahin RL (2004) Complementary and alternative medicine use among adults: United States, 2002. Adv Data 343: 1-19.

[21] Uchida S, Iha T, Yamaoka K, Nitta K, Sugano H (2012) Effect of biofield therapy in the human brain. J Altern and Complement Med 18: 875-879.

[22] Wilson CA (2011) Healing power beyond medicine. John Hunt Publishing Ltd., UK.

[23] Warber SL, Cornelio D, Straughn J, Kile G (2004) Biofield energy healing from the inside. J Altern Complement Med 10: 1107-1113.

[24] Prakash S, Chowdhury AR, Gupta A (2015) Monitoring the human health by measuring the biofield "aura": An overview. IJAER 10: 27637-27641.

[25] Trivedi MK, Patil S, Shettigar H, Bairwa K, Jana S (2015) Phenotypic and biotypic characterization of Klebsiella oxytoca: An impact of biofield treatment. J Microb Biochem Technol 7: 203-206.

[26] Trivedi MK, Patil S, Shettigar H, Gangwar M, Jana S (2015) An effect of biofield treatment on multidrug-resistant Burkholderia cepacia: A multihost pathogen. J Trop Dis 3: 167.

[27] Patil SA, Nayak GB, Barve SS, Tembe RP, Khan RR (2012) Impact of biofield treatment on growth and anatomical characteristics of Pogostemon cablin (Benth.). Biotechnology 11: 154-162.

[28] Nayak G, Altekar N (2015) Effect of biofield treatment on plant growth and adaptation. J Environ Health Sci 1: 1-9.
[29] Pavia DL, Lampman GM, Kriz GS (2001) Introduction to spectroscopy. (3rdedn), Thomson Learning, Singapore.

[30] Inoue M, Hirasawa I (2013) The relationship between crystal morphology and XRD peak intensity on $\mathrm{CaSO}_{4} \cdot 2 \mathrm{H}_{2} \mathrm{O}$. J Cryst Growth 380: 169-175.

[31] Zhang K, Alexandrov IV, Kilmametov AR, Valiev RZ, Lu K (1997) The crystallite-size dependence of structural parameters in pure ultrafine-grained copper. J Phys D Appl Phys 30: 3008-3015.

[32] Hellstern E, Fecht HJ, Fu Z, Johnson WL (1989) Stability of CsCl-type intermetallic compounds under ball milling. J Mater Res 4: 1292-1295.

[33] Fecht HJ, Hellstern E, Fu Z, Johnson WL (1990) Nanocrystalline metals prepared by high energy ball milling. Metall Trans A 21: 2333-2337.

[34] Eckert J, Holzer JC, Krill III CE, Johnson WL (1992) Structural and thermodynamic properties of nanocrystalline fcc metals prepared by mechanical attrition. Journal Mater Res 7: $1751-1761$

[35] Oleszak D, Shingu PH (1996) Nanocrystalline metals prepared by low energy ball milling. J Appl Phys 79: 2975.

[36] Dittrich M, Schumacher G (2014) Evolution of crystallite size, lattice parameter and internal strain in $\mathrm{Al}$ precipitates during high-energy ball milling of partly amorphous $\mathrm{Al}_{87} \mathrm{Ni}_{8} \mathrm{La}_{5}$ alloy. Mat Sci Eng A-Struct 604: 27-33.

[37] Vinila VS, Jacob R, Mony A, Nair HG, Issac S, et al. (2014) XRD studies on nano crystalline ceramic superconductor $\mathrm{PbSrCaCuO}$ at different treating temperatures. Cryst Struct Theory Appl 3: 1-9.

[38] Iqbal MZ, Ali S, Mirza MA (2008) Effect of particle size on the structural and transport properties of $\mathrm{La}_{0.67} \mathrm{Ca}_{0.33} \mathrm{MNO}_{3}$ nanoparticles. JNSMAC 48: 51-63. 